\title{
NOTES
}

\section{Hydrogen Production from Cellulose Derivative with the System Containing Mg Chlorophyll-a and Platinum Colloid}

\author{
Noriko HimESHIMA and Yutaka $\mathrm{AMAO}^{\dagger}$ \\ Department of Applied Chemistry, Oita Uinversity, Dannoharu 700, Oita 870-1192, Japan
}

(Received August 14, 2003; Accepted January 5, 2004)

\begin{abstract}
KEY WORDS Cellulose / Mg Chlorophyll- $a$ / Hydrogen Production / Platinum Colloid / Cellulase /
\end{abstract}

Hydrogen production system from renewable bioresources of timber waste, including cellulose and lignin, is important in energy source research fields. ${ }^{1-3}$ Cellulose and other polysaccharides can be hydrolyzed to monosaccharides, which can then be converted to hydrogen gas. Hydrogen production from glucose with glucose dehydrogenase (GDH) and a hydrogenase has been reported. ${ }^{45}$ Hydrogen production from glucose with GDH, hydrogenase and photoredox reaction with photosensitizer such as a zinc porphyrin also has been reported. ${ }^{6}$ Enzymatic photoinduced hydrogen production from polysaccharides, such as cellulose, has not received much attention. We previously reported enzymatic photoinduced hydrogen production from the oligosaccharide, sucrose, by the photosensitization of Mg chlorophyll- $a$ or artificial Zn chlorophyll- $a$ with platinum colloid. ${ }^{7,8}$ Photoinduced hydrogen production from polysaccharide, such as cellulose using the photosensitization of chlorophyll- $a$, has not been accomplished. Our investigation first focused on the development of a visible light-induced hydrogen production system by coupling cellulose from cotton hydrolysis using cellulase, with GDH and photoinduced hydrogen production with $\mathrm{Mg}$ chlorophyll- $a$ and platinum colloid. Cellulose did not hydrolyze enough using cellulase and
GDH, and no hydrogen production was observed. The degree of polymerization and molecular weight of the cellulose in the photoinduced hydrogen production system are important factors. Thus, relations among the degree of polymerization, molecular weight of cellulose and the amount of hydrogen production were examined using solubilized cellulose, methylcellulose as a cellulose model, in the photoinduced hydrogen production system.

This paper describes a hydrogen production system by coupling methylcellulose as a cellulose derivative hydrolysis using cellulase, with GDH and photoinduced hydrogen production with $\mathrm{Mg}$ chlorophyll- $a$ and platinum colloid as shown in Scheme 1, and the effect of polymerization degree of methylcellulose on the hydrogen production rate.

\section{EXPERIMENTAL}

\section{Materials}

Mg chlorophyll- $a$ from Spilurina, glucose dehydrogenase (GDH) from Bacillus sp. and methylcellulose were purchased from Wako Pure Chemical Industries, Ltd. Methylcellulose $\left(\mathrm{MC}_{n}\right)$ with average molecular weights of 15.000, 21.000, 26.000, 41.000, 63.000 and 86.000, are designated as the $\mathrm{MC}_{1}, \mathrm{MC}_{2}, \mathrm{MC}_{3}$,

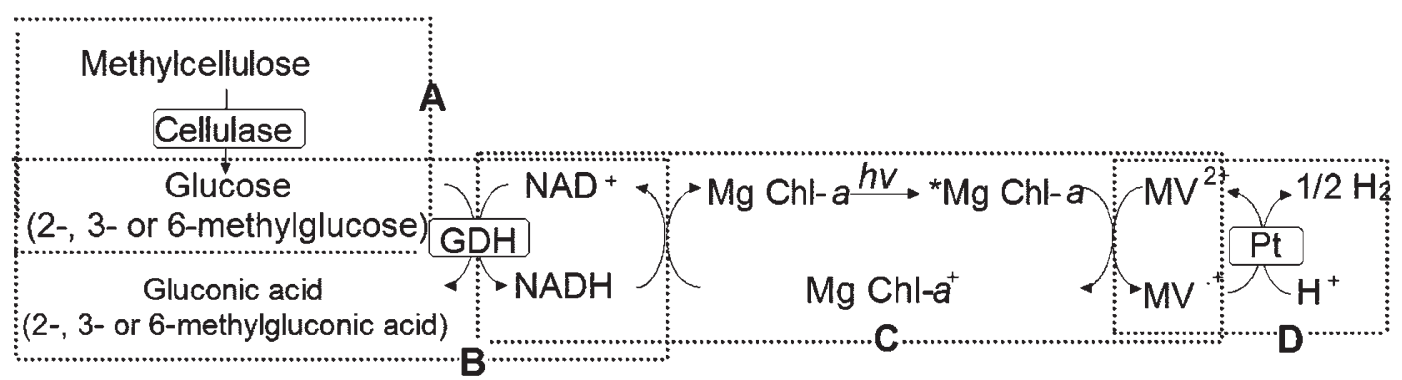

Scheme 1. Visible light-induced hydrogen production system coupling methylcellulose hydrolysis with cellulase and GDH and hydrogen production with platinum colloid by photosensitization of $\mathrm{Mg}$ chlorophyll- $a(\mathrm{Mg} \mathrm{Chl}-a)$ in the presence of methylviologen $\left(\mathrm{MV}^{2+}\right)$.

${ }^{\dagger}$ To whom correspondence should be addressed (E-mail: amao@cc.oita-u.ac.jp). 
$\mathrm{MC}_{4}, \mathrm{MC}_{5}$ and $\mathrm{MC}_{6} . \mathrm{NAD}^{+}$and $\mathrm{NADH}$, were purchased from Oriental Yeast Co., Ltd. Cellulase from Aspergillus niger was obtained from Sigma. Methylviologen dichloride and cetyltrimethylammonium bromide (CTAB) were from Tokyo Kasei Co., Ltd. One unit of GDH activity was defined as the amount of enzyme that would reduce $1 \mu \mathrm{mol} \mathrm{NAD}^{+}$to NADH by glucose per min. One unit of cellulase activity was defined as the amount of enzyme that would produce $1 \mu$ mol glucose by $\mathrm{MC}_{1}$ per min. As Mg chlorophyll- $a$ was solubilized in $10 \mathrm{mmol} \mathrm{dm}^{-3} \mathrm{CTAB}$.

\section{Preparation of Platinum Colloid}

Platinum colloid was prepared by refluxing hydrogen hexachloplatinate(IV) hexahydrate and sodium citrate as previously reported. ${ }^{9}$ The prepared platinum colloid released $0.7 \mu \mathrm{mol}$ hydrogen in the reaction system of $10 \mu \mathrm{L}$ platinum colloid, $120 \mu \mathrm{mol}$ methylviologen and $770 \mu \mathrm{mol}$ sodium dithionite in $4 \mathrm{~mL}$ of $50 \mathrm{mmol} \mathrm{dm}^{-3}$ Tris $/ \mathrm{HCl}$ buffer (pH 7.4) at $30^{\circ} \mathrm{C}$ for $10 \mathrm{~min}$. One unit of platinum colloid activity was defined as the release of $1 \mu \mathrm{mol}$ of hydrogen per min.

\section{NADH Formation with Cellulase, GDH and Methyl- cellulose}

The reaction was started by addition of $\mathrm{NAD}^{+}$ $(0.6 \mu \mathrm{mol})$ solution to the sample solution containing $\mathrm{MC}_{n}(1.2 \mu \mathrm{mol}$, cellobiose unit), cellulase (4.0 units) and GDH (5.0 units) in $3.0 \mathrm{~mL}$ of $10 \mathrm{mmol} \mathrm{dm}^{-3}$ phosphate buffer $(\mathrm{pH}=7.0)$. The reduction of $\mathrm{NAD}^{+}$ to NADH was determined with a UV-vis spectrophotometer (Multispec-1500 by Shimadzu Corp.) at $340 \mathrm{~nm}$ at a molar extinction coefficient of $6.3 \times$ $10^{3} \mathrm{~mol} \mathrm{dm}^{3} \mathrm{~cm}^{-1}$.

\section{Photoreduction of Methylviologen}

A methylviologen photoreduction system containing $\mathrm{NAD}^{+}, \mathrm{MC}_{n}, \mathrm{Mg}$ chlorophyll- $a$, methylviologen, cellulase and GDH (steps A, B and C in Scheme 1) was investigated. For photolysis under steady state irradiation, a $200 \mathrm{~W}$ tungsten lamp was used at $30^{\circ} \mathrm{C}$. The light of the wavelength less than $390 \mathrm{~nm}$ was cut a L-39 cut-off filter by Toshiba Corp. Reduction in methylviologen was determined using a UV-vis spectrophotometer at $605 \mathrm{~nm} .{ }^{10}$

\section{Visible-Light Induced Hydrogen Production}

Photoinduced hydrogen production from $\mathrm{MC}_{n}$ was carried out as follows. The sample solution containing $\mathrm{MC}_{n}$ ( $0.3 \mathrm{mmol}$ cellobiose unit), $\mathrm{Mg}$ chlorophyll- $a$ $(27 \mathrm{nmol})$, methylviologen $(1.2 \mu \mathrm{mol})$, colloidal platinum (0.5 unit), cellulase (4.0 units) and GDH (5.0 units) in $10 \mathrm{mmol} \mathrm{dm}^{-3}$ phosphate buffer $(\mathrm{pH}=7.0)$ was deaerated by freeze pump thaw cycle for 6 times and substituted by argon gas. $\mathrm{NAD}^{+}(10 \mu \mathrm{mol})$ solu- tion, deaerated and substituted by argon gas, was added to the above solution and the reaction was started by irradiation. Reaction volume was $3.0 \mathrm{~mL}$. The hydrogen produced was measured by gas chromatography (detector: TCD, column: active charcoal column, carrier gas: nitrogen).

\section{RESULTS AND DISCUSSION}

\section{NADH Formation with Cellulase, GDH and Methyl- cellulose System}

Methylglucose (2-, 3- or 6-methylglucose) or glucose formation from methylcellulose with cellulase was first measured. The reaction was started by cellulase (4.0 units) addition to the sample solution containing $\mathrm{MC}_{n}(1.2 \mu \mathrm{mol}$, cellobiose unit) in $3.0 \mathrm{~mL}$ $10 \mathrm{mmol} \mathrm{dm}^{-3}$ phosphate buffer $(\mathrm{pH}=7.0)$. For all systems using $\mathrm{MC}_{n}, 1.2 \mu \mathrm{mol}$ methylglucose or glucose was produced at $10 \mathrm{~min}$ incubation. This shows that the rate of methlycellulose hydrolysis to methylglucose or glucose with cellulase is very rapid. The yield was $c a .100 \%$ at $10 \mathrm{~min}$ incubation. When the sample solution containing $\mathrm{MC}_{n}$, cellulase, $\mathrm{NAD}^{+}$ and GDH was incubated, the time dependence of yield of $\mathrm{NAD}^{+}$to NADH is shown in Figure 1. For all systems using $\mathrm{MC}_{n}, 0.6 \mu \mathrm{mol} \mathrm{NADH}$ was formed and the yield of conversion of $\mathrm{NAD}^{+}$to NADH by the $\mathrm{MC}_{n}$ hydrolysis with cellulase and GDH was $100 \%$ after 40 min incubation. Little change in NADH formation rate was observed for any $\mathrm{MC}_{n}$, and thus, $\mathrm{MC}_{n}$ hydrolysis rate with cellulase (steps A in Scheme 1) is independent of the polymerization of $\mathrm{MC}_{n}$.

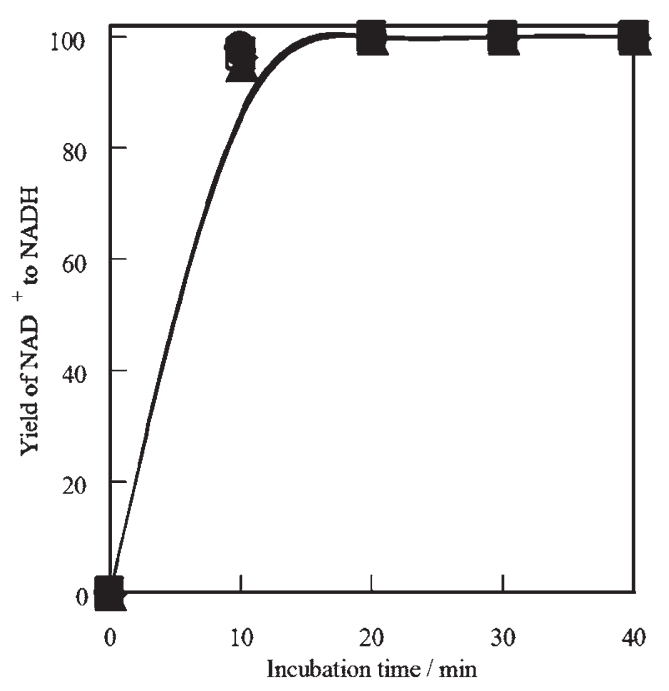

Figure 1. Time dependence of yield of $\mathrm{NAD}^{+}$to NADH with $\mathrm{MC}_{n}$ (1.2 $\mu \mathrm{mol}$ cellobiose unit), cellulase (4.0 units), $\mathrm{NAD}^{+}$ $(0.6 \mu \mathrm{mol})$ and GDH (5.0 units) in $3 \mathrm{~mL} 10 \mathrm{mmol} \mathrm{dm}^{-3}$ phosphate buffer ( $\mathrm{pH}$ 7.0). Closed square: $\mathrm{MC}_{1}$, closed circle: $\mathrm{MC}_{2}$, closed triangle: $\mathrm{MC}_{3}$, closed diamond: $\mathrm{MC}_{4}$, open square: $\mathrm{MC}_{5}$ and open circle: $\mathrm{MC}_{6}$. 


\section{Methylviologen Photoreduction}

When the deaerated sample solution containing $\mathrm{NAD}^{+}(7.5 \mu \mathrm{mol}), \mathrm{MC}_{n}(0.3 \mathrm{mmol}$ cellobiose unit), $\mathrm{Mg}$ chlorophyll- $a$ (27 nmol), methylviologen (1.2 $\mu \mathrm{mol})$, cellulase (4.0 units) and GDH (5.0 units) in $3.0 \mathrm{~mL}$ of $10 \mathrm{mmol} \mathrm{dm}^{-3}$ phosphate buffer $(\mathrm{pH}=$ 7.0) was irradiated, absorbance at $605 \mathrm{~nm}$ due to reduced methylviologen formation, increased with irradiation time. For all systems using $\mathrm{MC}_{n}, c a$. $1.2 \mu \mathrm{mol}$ reduced methylviologen was produced and the conversion of methylviologen to reduced methylviologen was $100 \%$ at $180 \mathrm{~min}$ irradiation. The methylviologen photoreduction rate was not affected by polymerization of $\mathrm{MC}_{n}$. No reduced methylviologen formation was observed without irradiation. Thus, the visible light-induced methylviologen reduction proceeds by coupling the $\mathrm{MC}_{n}$ hydrolysis with cellulase and GDH (steps A and B in Scheme 1) and methylviologen reduction with photosensitization of $\mathrm{Mg}$ chlorophyll-a (step C in Scheme 1).

\section{Visible-Light Induced Hydrogen Production}

The methylviologen photoreduction system containing $\mathrm{MC}_{n}$ (steps $\mathrm{A}, \mathrm{B}$ and $\mathrm{C}$ in Scheme 1) was realized and the photoinduced hydrogen production system was developed by adding platinum colloid to the methylviologen photoreduction system. When the sample solution was irradiated, hydrogen production was observed as shown in Figure 2. For all systems using $\mathrm{MC}_{n}$, hydrogen produced more than $4 \mathrm{~h}$, hydrogen production was above $10 \mu \mathrm{mol}$ after $4 \mathrm{~h}$ irradia-

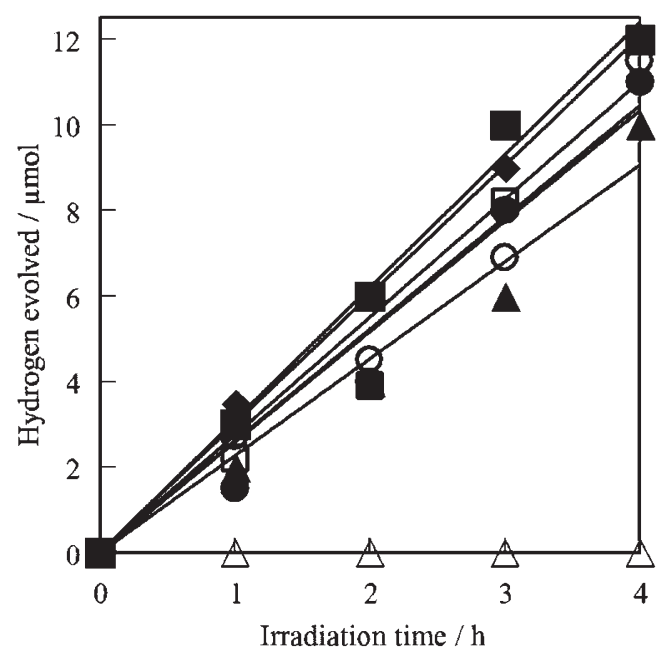

Figure 2. Time dependence of hydrogen production under steady state irradiation $\mathrm{MC}_{n}(0.3 \mathrm{mmol}$ cellobiose unit), cellulase (4.0 units), $\mathrm{NAD}^{+}$(7.5 $\left.\mu \mathrm{mol}\right), \mathrm{GDH}$ (5.0 units), Mg chlorophyll- $a$ $(27 \mathrm{nmol})$, methylviologen $(1.2 \mu \mathrm{mol})$ and platinum colloid $(0.5$ units) in $3 \mathrm{~mL}$ of $10 \mathrm{mmol} \mathrm{dm}^{-3}$ phosphate buffer ( $\mathrm{pH} \mathrm{7.0).} \mathrm{Closed}$ square: $\mathrm{MC}_{1}$, closed circle: $\mathrm{MC}_{2}$, closed triangle: $\mathrm{MC}_{3}$, closed diamond: $\mathrm{MC}_{4}$, open square: $\mathrm{MC}_{5}$, open circle: $\mathrm{MC}_{6}$ and open triangle: without irradiation. tion. For systems using $\mathrm{MC}_{1}$ and $\mathrm{MC}_{4}$, hydrogen production was $12 \mu \mathrm{mol}$. Hydrogen production was $10 \mu \mathrm{mol}$ in the system using $\mathrm{MC}_{2}$. Hydrogen production rate is thus independent of polymerization of $\mathrm{MC}_{n}$. For all systems using $\mathrm{MC}_{n}$, quantum yield was $c a .2 .0 \%$ by the potassium ferrioxalate actinometry method. ${ }^{11}$ In all cases, hydrogen production was larger than that of the initial $\mathrm{NAD}^{+}(7.5 \mu \mathrm{mol})$. This indicates that NADH formed by cellulase and GDH is oxidized to $\mathrm{NAD}^{+}$in photoinduced hydrogen production and $\mathrm{NAD}^{+}$is reduced to $\mathrm{NADH}$ by $\mathrm{MC}_{n}$ hydrolysis with cellulase and $\mathrm{GDH}$, and then $\mathrm{NADH}$ serves as electron donor in photoinduced hydrogen production. No hydrogen was produced in the absence of $\mathrm{NAD}^{+}$in the above system. No hydrogen production was observed without irradiation as shown in Figure 2. Visible light-induced hydrogen production may thus proceed by coupling $\mathrm{MC}_{n}$ hydrolysis with cellulase and GDH (steps A and B in Scheme 1) and hydrogen production with platinum colloid using the photosensitization of Mg chlorophyll- $a$ (steps C and $\mathrm{D}$ in Scheme 1). Steady hydrogen production was observed at over $8 \mathrm{~h}$ irradiation. Product inhibition and deactivation of enzymes hardly occur in this reaction system.

\section{CONCLUSIONS}

Hydrogen production system coupling $\mathrm{MC}_{n}$ hydrolysis and hydrogen production with visible light-induced photosensitization of Mg chlorophyll- $a$ was developed and continuous hydrogen gas production was achieved. Hydrogen production rate was not affected by the polymerization of $\mathrm{MC}_{n}$. The cellulose derivative as a renewable bioresource is used effectively to produce environmentally clean, hydrogen as energy. Further research will bring about development of a hydrogen production system form cellulose contained in actual timber waste by photosensitization of $\mathrm{Mg}$ chlorophyll- $a$.

Acknowledgment. This work is partially supported by The Japan Securities Scholarship Foundation.

\section{REFERENCES}

1. L. C. Helena and R. P. Overend, Fuel Process Technol., 71, 187 (2001).

2. M. J. Barbosa, J. M. Rocha, J. Tramper, and R. H. Wijffels, J. Biotechnol., 85, 25 (2001).

3. L. Garcia, R. French, S. Czernik, and E. Chornet, Appl. Catal., A: General, 201, 225 (2000).

4. J. Woodward, M. Orr, K. Cordary, and E. Greenbaum, Nature, 405, 1014 (2000).

5. T. Inoue, S. N. Kumar, T. Kamachi, and I. Okura, Chem. 
Hydrogen Production from Cellulose with Mg Chlorophyll- $a$

Lett., 1999, 147.

6. T. Inoue, T. Kamachi, and I. Okura, Porphyrin, 8, 29 (1999).

7. Y. Saiki and Y. Amao, Bioconjugate Chem., 13, 898 (2002).

8. Y. Takeuchi and Y. Amao, Bioconjugate Chem., 14, 268 (2003).

9. J. Kiwi and M. Grätzel, J. Am. Chem. Soc., 101, 7214
(1979).

10. T. Watanabe and K. Honda, J. Phys. Chem., 86, 2617 (1982).

11. C. G. Hatchard and C. A. Parker, Proc. R. Soc., Ser. A, 235, 518 (1956). 